\title{
Revisiting automated project management in the digital age - a survey of AI approaches
}

\author{
Gunnar Auth, Leipzig University of Telecommunications, Germany, auth@hft-leipzig.de \\ Oliver Jokisch, Leipzig University of Telecommunications, Germany, jokisch@hft-leipzig.de \\ Christian Dürk, Corivus AG, Germany, christian.duerk@corivus.de
}

\begin{abstract}
In this decade, remarkable progress has been made in the field of artificial intelligence (AI). Inspired by well-known services of cognitive assistance systems such as IBM Watson, Apple's Siri or Google Duplex, AI concepts and algorithms are widely discussed regarding their automation potentials in business, politics and society. At first glance, project management (PM) seems to be less suitable for automation due to the inherent uniqueness of projects by definition. However, AI is also creating new application possibilities in the PM area, which will be explored in this contribution by involving an extensive literature review as well as real-world examples. The objective of this article is to provide a current overview of AI approaches and available tools that can be used for automating tasks in business project management.
\end{abstract}

Keywords: Artificial intelligence, project management, automation, machine learning, bot.

\section{Introduction}

The recent rise in expectations of Artificial Intelligence (AI) performance in automating complex activities (e.g., PwC, 2018a) is also reflected in the discussion on the future of project management (PM). In addition to the various possible uses of AI methods in PM such as Support Vector Machines (Wauters \& Vanhoucke, 2014) or Predictive Analytics (Fauser, Schmidthuysen, \& Scheffold, 2015), the discussion also revolves around the question of whether or when the human project manager will be replaceable by AI (e.g., Bailey, 2017; Burger, 2017; $\&$ PwC, 2018b). Particularly optimistic authors are already predicting a revolution in PM, driven by AI (e.g., Birch, 2018; Branscombe, 2018).

As a generic term Automated Project Management (APM) summarizes all approaches for the most complete automation of PM tasks and activities. The use of the term can already be found in the early 1980s (Smith \& Mills, 1983). From the available literature, we identified two different meanings of APM: as part of the related term Automated Project Management System (APMS) it focuses on special software systems supporting project scheduling and controlling in terms of time, resources and cost (Nicols, 1986). A second, narrower meaning of APM can be located in software engineering where it describes the automation of software development tasks, which are typically organized as a software project (Campbell \& Terwilliger, 1986). In parallel, expert systems had evolved and become popular, leading to a growing supply of commercial software solutions (Liebowitz, 1997). Nevertheless, APMS were not designed as expert systems. 
The use of AI was not a central characteristic of early APMS designs. Still, the discussion of AI potentials for project management also started around that time (e.g., Hosley, 1987) and has recently become vital again (e.g., Wang, 2019).

The high expectations of AI technology in earlier times, which can be observed in a similar way today (see Gartner, 2017; PwC, 2018a), lead to ambitious development plans for knowledgebased decision support along the entire project lifecycle (Hosley, 1987; Levitt \& Kunz, 1987). However, the so-called AI winter (Russel \& Norvig, 2010) made such early approaches disappear from practical use a little later due to unfulfilled expectations. With the recently rekindled AI enthusiasm, the term APM has been rediscovered and loaded with a tighter relationship to AI (Jordan, 2018). The latest advances in AI development increasingly pose the question of substitutability of the human project leader (Bailey, 2017; Pielmeier \& Lommel, 2017; PwC, 2018b). With the extended possibilities of AI-based automation through novel procedures and extensive data availability (Bitkom \& DFKI, 2017), the question again arises in project management, which potentials for automation can be realized in view of the current state of development and which future development trends are already emerging. For this purpose, new term creations such as Data-driven Project Management, Predictive Project Analytics or Project Management Bot need to be clarified and evaluated.

This article contributes to the discussion of using AI for automation in project management from an application-oriented perspective. The objective of the presented survey is to provide a current overview of AI approaches and available real-world applications that can be used for automating tasks in business project management. In order to understand and to conceptualize the role of AI in project management, we started our research with a literature review focused on research outcomes and applications following Brocke et al. (2009). The search engines and electronic databases we used included Google Scholar, SpringerLink, IEEE Xplore, and ReserachGate. From the review results we defined a conceptual framework for AI applications in PM, which is presented in the next section. The data for the application-oriented part of our study is mainly based on vendor-side and third-party information resulting from a second search process based on the conceptual framework and using Google Web search as well as the academic search tools mentioned before. In subsequent section, we summarize the search results in an overview of current AI applications in PM structured into the three main categories 1) Data-driven project management, 2) AI platforms for PM, and 3) Project management bots. With the last section we conclude the paper.

\section{From Process to Project Automation with AI}

In the era of digitalization with its transformation processes in business and society, driven by rapid developments and high processing speed in information and communication technology (ICT), the feasibility limits of automating human tasks seem to soar. This was impressively demonstrated 2016 by Google's software AlphaGo, which won four of five matches against the 18-time world champion of the board game Go, Lee Sedol. Such an AI performance was not expected before, due to the complexity of Go, although already in 1997, IBM's super computer DeepBlue had beaten the world champion of Chess, Garry Kasparov. In 2018, the system Google Duplex was presented, which can automatically make appointments via telephone with human 
agents using natural language. In the given examples, the persons did not even seem to notice that they were talking to a machine (Leviathan \& Matias, 2018).

\section{Requirements of Progressive Automation}

Automation can be defined as the technology by which a process or procedure is performed with a minimum of human assistance (e.g., Groover, 2008). For a long time, the according technical system could only be constructed as a finite state machine. Program-controlled automation technology, such as looms with punch card control, considerably expanded the automation capability of processes and tasks at the beginning of the $19^{\text {th }}$ century. Throughout time, the limits of automation were always determined by the current state-of-the-art in technology. At the end of the $20^{\text {th }}$ century, the amount of information processing required to perform a task was considered as a limiting factor. Recently, the available ICT has progressed so much through advances in AI that the general automation capability has also expanded enormously (Bitkom \& DFKI, 2017). Therefore, it is hardly surprising that high expectations are currently being made of the potential of automation. For the German economy alone, the accounting firm PricewaterhouseCoopers (PwC) estimated the added value potential of AI by the year 2030 at a total of around 430 billion euros (PwC, 2018a). PwC was not only focusing on work processes, which are more easily accessible to automation due to their repetitive nature on the basis of previously defined solutions and fixed decision parameters. Moreover, the PwC (2018a) study highlighted learning AI systems that can adapt to new situations and act without human support. This allows for bringing projects into the focus of application. A project can be compared to a Go game, which demands creativity, intuition and strategic thinking from the player (or project manager). As prerequisites basic cognitive skills are necessary which are characteristic of human intelligence, such as audiovisual cognition, memory, learning, planning and problem solving.

\section{A Conceptualization of AI for Project Automation}

According to Russell and Norvig (2010), AI is concerned with the development of intelligent agents, which can perceive their environment and carry out derived actions. Furthermore, such artificial systems have the ability to (1) act autonomously, (2) persist for longer, (3) adapt to changes, and (4) set and track objectives (Russel \& Norvig, 2010). With regard to the successful planning and execution of projects, so-called rational agents suggest a particular potential: their extended capabilities enable them to strive for the best result in their actions or the most valued result under uncertainty. Regarding its application-oriented scientific context, AI is utilizing models and methods of mathematics, statistics/stochastics, computer science, psychology and of cognition and neuroscience. For more complex applications, agents often process large amounts of formalized knowledge, which in turn is derived from data (Rowley, 2007). Through this connection between knowledge and data, concepts from the field of data management are also relevant in the discussion about AI, but their references to AI are not always clearly demarcated. With regard to the practical focus of this article, these terms include in particular Business Intelligence (BI), Analytics and Big Data. In contrast to AI, BI pursues a specific application reference, which is centered around the support of human decision-makers in operational decision-making processes through appropriate information provision (Schieder, 2016). The term BI is strongly influenced by certain technical implementation concepts such as multidimensional analysis, dashboards and reporting. However, the term analytics has a more neutral, technically 
oriented focus, but nevertheless aims at more specific "local" decision support from a technical point of view (Winter, 2016). Big Data, probably the most recent term in this series, extends the already mentioned concepts by "new" technological possibilities for processing and using extremely large (feature volume) or rapidly growing (velocity) as well as strongly heterogeneous (variety) data sets (Dittmar, 2016). In turn, AI systems or methods can be used in all three concepts as tools to achieve advanced purposes. The combination of methods of AI with data analysis methods in the field of the above-mentioned concepts (e.g., data mining) has led to the development of new conceptual creations such as predictive analytics, advanced analytics or data-driven AI (Bencke, 2017; Gluchowski, 2016). To create a conceptual framework for AI in the PM domain, we followed the organization of AI topics, related concepts and procedures by Russel and Norvig (2010) as well as combined it with the AI taxonomy by Davis, Hoffert, and Vanlandingham (2016). We also made adaptations by leaving out nonrelevant elements and aggregating other elements according to our research objectives based on personal judgment. The result of this conceptualization is shown in Table 1. Guided by this framework, the search for AI applications in PM was carried out - summarized in the according section.

Table 1. Conceptual Framework for This Study Based on Russel and Norvig (2010) as well as Davis, Hoffert, and Vanlandingham (2016)

\begin{tabular}{|c|c|c|}
\hline 1. Problem solving & $\begin{array}{l}\text { 2. Knowledge representation } \\
\text { and deduction }\end{array}$ & 3. Machine learning \\
\hline Algorithmic search & Data/text mining & Learning with or w/o supervisor \\
\hline Blind search & Ontology & Reinforcement learning \\
\hline Heuristic search & Expert system & Support vector machines \\
\hline Adversarial search & (Multi-)agent system & Neural network \\
\hline \multirow[t]{2}{*}{ Constraint satisfaction } & Bayes network & Deep learning \\
\hline & Decision tree or forest & Predictive analytics \\
\hline 4. Communication & 5. Perception \& recognition & 6. Robotics \\
\hline Natural language processing & Text recognition & Locomotion \\
\hline Translation & Image or audio classification & Sensor elements \\
\hline Text generation & Speech recognition & Actuating elements \\
\hline Speech synthesis & 3D-world reconstruction & \\
\hline
\end{tabular}

\section{A Unified Understanding of Project Management}

So far, it has become clear that AI is a multi-layered and diverse term. However, the second central term in the focus of this article - project management - is hardly different in this regard. Although the basic meaning is largely consensual, closer examination opens up a very broad and dynamic spectrum of content-related conceptual components and their characteristics, such as 
sub-areas, process models, roles and structures, methods, techniques or types of projects. This diversity is offset by many years of standardization efforts in the PM discipline that provided accepted definitions of terms. From a task-oriented perspective, the ISO 21500 and ANSI/IEEE PMI PMBOK international standards consistently identify ten subfields of PM (ISO, 2012; PMI, 2017): (1) integration, (2) stakeholders, (3) scope, (4) (human) resource, (5) Time, (6) Cost, (7) Quality, (8) Risk, (9) Procurement, (10) Communication, which are integrated into a five-phase project lifecycle in which the two standards also agree (except for marginal differences in phase designations): (1) Initiating, (2) Planning, (3) Implementing / Executing, (4) Monitoring and Controlling, (5) Closing.

\section{AI Applications in The Domain of Project Management}

Ever since the beginning of the development of AI systems, the key question that has remained immanent to date was: Can a human-developed technical system have human intelligence? Alan Turing already investigated this question in 1950 with the still relevant Turing test. Due to the close relationship between AI, knowledge and data processing, the limitations of AI have always been defined by the power of Information Technology (IT) in terms of data volume and processing speed. Rich (1983) put it in a nutshell as early as 1983 with her AI definition: "Artificial Intelligence is the study of how to make computers do things at which, at the moment, people are better" (p. 1). In the following, three categories are presented, which were identified as content-related focal points within the results of our investigation on the current state of AI development in project management. The succession of the categories results from an increasing proportion of 'strong' AI.

\section{Data-Driven Project Management}

The core idea of data-driven project management (DdPM) is well-known - the more relevant information about a decision problem is available, the more reliable the best decision alternative can be selected (Sullivan III, 2016). Since information is based on data, any PM decision should be founded on a solid data basis (L \& George, 2004). In the DdPM notion, this database needs to be combined with experience and intuition of a human project manager to actually make decisions (L \& George, 2004; Vanhoucke, 2018). DdPM's focus is initially on the classic problem of resource-constrained project scheduling and thus the planning and controlling functions in terms of time, costs, risks and quality (Vanhoucke, 2012). The repertoire of methods includes known mathematical-statistical methods such as Program Evaluation and Review Technique (PERT), Critical Path or Chain, Earned Value Management (EVM), Analytical Hierarchy Process (AHP), and (Lean) Six Sigma.

In the course of the digitalization, however, more and more data as well as high-performance IT infrastructure is available for processing. Against this background, DdPM increasingly uses analytical methods. These pick up the results of classical, past or present-oriented methods to derive predictions about future developments (hence predictive analytics). For example, Singh (2015) described processes and application examples based on linear regression for the prediction of cost changes through extension of project scope and duration for the PM area. Since the informational value of predictive analytics results depends heavily on the amount of data and the number of variables, special data analysis tools are indispensable for practical 
application. Some authors (Duggal, 2018; Ou, 2007; Rechenthin, 2013) summarized this new development under the term Project Intelligence (based on Business Intelligence), which has not yet been widely accepted.

\section{AI Platforms for Project Management}

AI platforms for PM can be understood as an evolution stage of DdPM, targeted to unlocking new potential through AI in the context of big data and analytics (Ruchi \& Srinath, 2018). Because of the combination of high implementation effort for a single company on the one hand and high user expectations on the other hand, certain vendors have developed cloud-based service platforms that provide AI-based services.

As a well-known company, for example, the consulting firm Deloitte offers a consulting service under the name Predictive Project Analytics, which is based on a special analytics engine combined with a comprehensive database, which was obtained from more than 2,000 projects (Fauser, 2015). Furthermore, neural networks and generic algorithms are used (Fauser, 2015), extending the conventional DdPM approach. Key areas of application include complexity and success analyses, risk assessments and employee selection for project teams (Deloitte, 2016). Team member selection is also featured by other application examples based on the platform approach. E.g., startup Cloverleaf develops software for the compilation of project teams using employee data, which, in addition to characteristics such as experience and qualifications, also takes into account "invisible facets of a person", e.g., the ability to adapt to the desired working model or the agreement with (work) cultural values (Cloverleaf, 2018). A more comprehensive approach is pursued by the Californian vendor TARA with its eponymous platform. Originally designed to automate the recruiting process for external software developers, the focus has now greatly expanded towards project planning and monitoring (TARA, 2018). TARA uses machine learning to automate the initial definition of the project focus, task and time planning, creating the project team as well as monitoring and forecasting for the current project.

\section{Project Management Bots}

The term Project Management Bots (PMB) was coined in 2017 by consulting firm Gartner in the Hype Cycle for Project and Portfolio Management (Schoen, 2017), meaning a class of intelligent software agents specializing in project management. In contrast to RPA bots, however, the focus on graphical user interfaces is missing. PMB are more likely to be equipped with speech or text interfaces for communicating with humans, and thus have features of chatbots (Gaton, 2017). While a bot externally presents itself as one actor through one or more central communication interfaces, in the case of bots with extended capabilities, it is mostly multi-agent systems. These are characterized by the fact that the associated agents interact with each other in order to achieve a common goal (Olfati-Saber, Fax, \& Murray, 2007). For example, interaction can take the form of negotiation and is based on communication between the agents. Considerations to apply multi-agent systems in project management are already much older than the new term creation PMB (de Medeiros Baia, 2015; Petrie, Goldmann, \& Raquet, 1999; Yan, Kuphal, \& Bode, 2000). What is new, however, is that today not only research prototypes but also commercial products are available for practical use, due to the technological developments of recent years. PMB solutions are often based on a proprietary cloud platform that enables server- 
side storing and processing of data as well as communication with and between client-side bot components. The current product range for PMB can be divided into three categories:

(1) Independent products specialized in PM such as PMOtto, which is offered by a Danish startup of the same name and is also referred to as the "Personal Project Management Assistant" (PMOtto, 2018). PMOtto assists human users in working with conventional PM software (Currently, only Microsoft Project online, which is part of the Office365 cloud software package, is supported). For this purpose, the bot understands natural language, which it transforms into operating steps for the PM software and executes it. The system continues to learn with machine learning and is thus able to improve recommendations.

(2) Vendor-side extensions of established products to support project teams. Currently, these are mainly found in the field of modern collaboration and communication tools such as Microsoft Teams. This product was launched in 2017 and is a communications service for teams integrated in the Office 365 product family. Teams includes two preinstalled chatbots, T[each]-bot and Who-bot (McDonald, 2016). T-bot supports new users in learning system operations. Who-bot can answer questions of the type "Who knows about $x "$ and analyse communication via teams. Beyond the relatively simple functionality, the two bots demonstrate the integrated functionality for developing custom bots.

(3) Extensions for established third-party products. Especially for the Atlassian products Jira, Confluence and HipChat/Stride a larger range of bot extensions has been developed. For example, the company Stratejos offers a Project Assistant Bot for Atlassian products that supports project teams in data entry and editing, risk analysis and project monitoring (Baldassarre, 2018).

\section{Further AI-Related Aspects in Project Management}

In addition to the previous AI examples in the domain of project management, a few close-knit areas of development can be identified, such as Intelligent Information Management (IIM), which emphasizes the integration of current AI processes and technology into information management (e.g., Bailin \& Truszkowski, 2001). The potential of IIM is closely linked to project management information systems (PMIS) (PMI, 2017). Furthermore, Robotic Process Automation (RPA) is suited for well-structured, less complex routine tasks, in which the term "robotic" refers to software agents ("robots") that are able to learn manual activities and then perform them automatically (van der Aalst, Bichler, \& Heinzl, 2018). PM is not within the primary focus, but RPA may include monitoring and controlling of projects (e.g., to keep thresholds) (Sharma, 2017), reporting and documentation (which is similar to IIM) or even planning and optimization (Branscombe, 2018).

\section{Conclusions}

With regard to the initial question about the substitutability of the human project leader by AI, based on our investigation of the current state of research and development, the first all-clear can be given. The expectations exceed (still) today's possibilities. In particular, the solutions available in practice hardly meet the requirements of ambitious terms such as Automated Project 
Management or Project Management Bot. The broad and dynamic field of tasks of a project manager can currently only be automated in small, clearly defined areas. In the metaphor of an autopilot, today's situation is more like a car with early assistance systems such as ABS and ESP than a Tesla or Google Driverless Car. However, the development is very fast and prototypes like Google Duplex give an impression of realistic potential. Much is already technically feasible, but still needs to be brought to product maturity. So, if the technical feasibility fades into the background, is it only a matter of time until APM becomes reality?

The results of our study point the way to further research. In general, we found a number of interesting approaches and use cases for AI in PM. To understand the potential of AI for PM even better, a business process perspective seems to be appropriate. Nowadays, PM is widely considered as a set of specific business processes; standards like ISO and PMI describe normative process models. This allows for evaluating new methods for process automation and digitalization (e.g., Denner, Püschel, \& Röglinger, 2018) whether they could be adapted for identifying and exploiting the potential of PM processes for AI-based automation.

Apart from implementation questions, AI technology in particular raises questions of acceptance, reliability, transparency and legal as well as ethical and moral responsibility. While these have been discussed in other areas of application such as autonomous driving for some time, the discussion in project management is still in its infancy. Here, too, the wheel does not have to be re-invented. Scientifically, for example, information ethics deals with relevant questions and provides answers (Bendel, 2016). In practice, first companies have begun to create guidelines and framework conditions on this basis. For example, Deutsche Telekom has recently issued "Guidelines for the Use of Artificial Intelligence" (Fulde, 2018). In addition to the further development of the technical possibilities, the respective implications for the ethics of project management must be constantly re-examined and evaluated.

\section{References}

Bailey, G. (2017). Will AI replace the project manager? ITProPortal. Retrieved from https://www.itproportal.com/features/will-ai-replace-the-project-manager/

Bailin, S. C., \& Truszkowski, W. (2001). Ontology negotiation between agents supporting intelligent information management. Proceedings of the Workshop on Ontologies in Agent Systems, 5th International Conference on Autonomous Agents, Montreal, Canada.

Baldassarre, G. (2018). Stratejos helps teams manage daily admin and coordination of projects. Retrieved from https:/www.startupdaily.net/2018/07/stratejos-helps-teams-managedaily-admin-coordination-projects/

Bencke, M. (2017). Why 2017 is the year of data-driven AI. VentureBeat. Retrieved from https://venturebeat.com/2017/01/17/why-2017-is-the-year-of-data-driven-ai/

Bendel, O. (2016). 300 keywords informationsethik: Grundwissen aus computer-, netz- und neue-medien-ethik sowie maschinenethik. Wiesbaden: Springer Gabler (in German). 
Birch, D. (2018). The potential for artificial intelligence to revolutionise project management. PM Today. Retrieved from https://www.pmtoday.co.uk/articles/the-potential-forartificial-intelligence-to-revolutionise-project-management/

Federal Association for Information Technology, Telecommunications and New Media (Bitkom) \&German Research Center for Artificial Intelligence (DFKI) (2017). Artificial intelligence - economic importance, social challenges, human responsibility. Position paper. Retrieved from https://www.bitkom.org/sites/default/files/file/import/171101-PPArtificial-Intelligence-ENG-Web.pdf

Branscombe, M. (2018). How AI could revolutionize project management. Retrieved from https://www.cio.com/article/3245773/project-management/how-ai-could-revolutionizeproject-management.html

Brocke, J. v., Simons, A., Niehaves, B., Reimer, K., Plattfaut, R., \& Cleven, A. (2009). Reconstructing the giant: On the importance of rigour in documenting the literature search process. Proceedings of the 17th European Conference on Information Systems (ECIS), Verona, Italy, Paper 161, Retrieved from http://aisel.aisnet.org/ecis2009/161

Burger, R. (2017). I, project manager: The rise of artificial intelligence in the workplace. Retrieved from https://blog.capterra.com/i-project-manager-the-rise-of-artificialintelligence-in-the-workplace/

Campbell, R. H., \& Terwilliger, R. B. (1986). The SAGA approach to automated project management. In Conradi, R., Didriksen, T. M., \& Wanvik, D. H. (Eds.). Advanced Programming Environments. Proceedings of an International Workshop. Trondheim, Norway: Springer, LNCS 244, pp. 142-155.

Cloverleaf (2018). About - Cloverleaf. Retrieved from https://cloverleaf.me/about

Davis, J., Hoffert, J., \& Vanlandingham, E. (2016). A taxonomy of artificial intelligence approaches for adaptive distributed real-time embedded systems. Proceedings of the 2016 IEEE International Conference on Electro Information Technology (EIT). http://doi.org/10.1109/EIT.2016.7535246

de Medeiros Baia, D. (2015). An integrated multi-agent-based simulation approach to support software project management. Proceedings of the $37^{\text {th }}$ International Conference on Software Engineering - Vol. 2, Florence, Italy, pp. 911-914.

Denner, M.-S., Püschel, L. C., \& Röglinger, M. (2018). How to exploit the digitalization potential of business processes. Business Information Systems Engineering, 60(4), 331349.

Deloitte The Netherlands (2016): Predictive project analytics 2.0. Retrieved from https://www2.deloitte.com/content/dam/Deloitte/nl/Documents/technology/deloitte-nlcons-technology-predictive-project-analytics.pdf

Dittmar, C. (2016). Die nächste evolutionsstufe von AIS: Big data - Erweiterung klassischer BIarchitekturen mit neuen big data technologien. In Gluchowski, \& Chamoni, 2016 (pp. 55-65, in German). 
Duggal, J. (2018). The DNA of strategy execution: Next generation project management and $P M O$. Hoboken, NJ: Wiley.

Fauser, J., Schmidthuysen, M., \& Scheffold, B. (2015). The prediction of success in project management - predictive project analytics. projektManagement aktuell, 5/2015, 66-74.

Fulde, V. (2018). We need a "Digital Ethics" policy: Deutsche Telekom defines its own policy for the use of artificial intelligence. Retrieved from https://www.telekom.com/en/ company/digital-responsibility/details/we-need-a-digital-ethics-policy-524364

Gaton, J. (2017). Rise of the project bots. Microsoft Project User Group (MPUG). Retrieved from https://www.mpug.com/articles/rise-project-bots/

Gartner, Inc. (2017). Gartner identifies three megatrends that will drive digital business into the next decade. Retrieved from https://www.gartner.com/en/newsroom/pressreleases/2017-08-15-gartner-identifies-three-megatrends-that-will-drive-digitalbusiness-into-the-next-decade

Gluchowski, P., \& Chamoni, P. (Eds.). (2016). Analytische informationssysteme - business intelligence-technologien und-anwendungen ( $5^{\text {th }}$ ed.). Wiesbaden: Springer Gabler (in German).

Gluchowski, P. (2016). Entwicklungstendenzen bei analytischen informationssystemen. In Gluchowski, \& Chamoni (pp. 225-238, in German).

Groover, M. P. (3rd ed.). (2008). Automation, production systems, and computer integrated manufacturing. Upper Saddle River, NJ: Pearson Prentice-Hall.

Hosley, W. N. (1987). The application of artificial intelligence software to project management. Project Management Journal, 18(3), 73-75.

International Organization for Standardization (ISO) (2012). ISO 21500:2012 - Guidance on project management.

Jordan, A. (2018). Automated project management? Retrieved from https://www.project management.com/articles/449492/Automated-Project-Management-

L, B., \& George, A. (2004). Data driven project management - a scientific art. Presented at Annual Project Management Leadership Conference, Bangalore, India, 2004. Retrieved from http://citeseerx.ist.psu.edu/viewdoc/download?doi=10.1.1.203.1022\&rep $=$ rep $1 \&$ type $=$ pdf

Levitt, R. E., \& Kunz, J. C. (1987). Using artificial intelligence techniques to support project management. Artificial Intelligence for Engineering Design, Analysis and Manufacturing, 1(1), 3-24.

Leviathan, Y., \& Matias, Y. (2018). Google duplex: An AI system for accomplishing real-world tasks over the phone. Retrieved from https://ai.googleblog.com/2018/05/duplex-aisystem-for-natural-conversation.html

Liebowitz, J. (1997). The handbook of applied expert systems. Boca Raton, Florida: CRC Press. 
McDonald, K. (2016). Microsoft teams introduces T-Bot and Who-Bot. Retrieved from https://www.onmsft.com/news/microsoft-teams-introduces-t-bot-and-who-bot

Nicols, J. (1986). Selecting an automated project management system. International Journal of Project Management, 4(3), 132-137.

Olfati-Saber, R., Fax, J. A., \& Murray, R. M. (2007). Consensus and cooperation in networked multi-agent systems. Proceedings of the IEEE, 95(1), 215-233.

Ou, R. (2007). Project intelligence. Proceedings of the $25^{\text {th }}$ Annual Pacific Northwest Software Quality Conference, Portland, Oregon, 267-274.

Petrie, C., Goldmann, S., \& Raquet, A. (1999): Agent-based project management. In Woolridge, M., \& Veloso, M. (eds.), Artificial intelligence today: Recent trends and developments (pp. 339-364). Berlin, Germany: Springer.

Pielmeier, H., \& Lommel, A. (2017). Will AI eliminate the need for project managers? Common Sense Advisory. Retrieved from http://www.commonsenseadvisory.com/abstractview/ tabid/74/articleid/48488/title/willaieliminatetheneedforprojectmanagers/default.aspx

Project Management Institute (PMI) (2017). A guide to the project management body of knowledge (PMBOK ${ }^{\circledR}$ Guide, 6th ed.).

PMOtto (2018). PMOtto - What I do. Retrieved from https://www.pmotto.ai/\#comp-ioig0sqf

PricewaterhouseCoopers (PwC) (2018a). Impact of Artificial Intelligence in Germany. Retrieved June 06, 2018 from https:/www.pwc.de/de/business-analytics/sizing-the-price.pdf

PricewaterhouseCoopers (PwC) (2018b). AI will transform project management. Are you ready? Retrieved June 06, 2018 from https://news.pwc.ch/wp-content/uploads/2018/04/AI-willtransform-PM-Whitepaper_EN_web.pdf

Rechenthin, D. (2013). Project intelligence. Project Management Institute.

Rich, E. (1983). Artificial intelligence. New York: McGraw-Hill.

Rowley, J. (2007). The wisdom hierarchy: Representations of the DIKW hierarchy. Journal of Information Science, 33(2), 163-180.

Ruchi, S., Srinath, P. (2018). Big data platform for enterprise project management digitization using Machine learning. Proceedings of the $2^{\text {nd }}$ International Conference on Electronics, Communication and Aerospace Technology (ICECA), Coimbatore, India. http://doi.org/10.1109/ICECA.2018.8474799

Russell, S. J., \& Norvig, P. (2010). Artificial intelligence - A modern approach (3rd ed.). Upper Saddle River, NJ: Prentice Hall.

Schieder, C. (2016). Historische fragmente einer integrationsdisziplin-Beitrag zur konstruktgeschichte der business intelligence. In Gluchowski \& Chamoni (pp. 13-32, in German).

Schoen, M. (2017). Hype cycle for project and portfolio management, 2017. Retrieved from https://www.gartner.com/doc/3772090/hype-cycle-project-portfolio-management 
Sharma, R. (2017). How to leverage RPA (Robotic Process Automation) in PM? Online discussion in forum Project Management Central. Retrieved from https://www.projectmanagement.com/discussion-topic/81074/How-to-leverage-RPA-Robotic-Process-Automation--in-PM-

Singh, H. (2015). Project management analytics - A data-driven approach to making rational and effective project decisions. Old Tappan, NJ: Pearson Education.

Smith, L. A., \& Mills, J. (1983). Reporting characteristics of automated project management systems. International Journal of Project Management, 1(3), 155-159.

Sullivan III, M. (2016). Statistics: Informed decisions using data (5 ${ }^{\text {th }}$ ed.). Harlow, England: Pearson.

TARA (2018). How TARA works. Retrieved from https://tara.ai/how-it-works/

van der Aalst, W. M. P., Bichler, M., \& Heinzl, A. (2018). Robotic process automation. Business Information Systems Engineering, 60(4), 269-272.

Vanhoucke, M. (2012). Project management with dynamic scheduling: Baseline scheduling, risk analysis and project control. Berlin, Germany: Springer.

Vanhoucke, M. (2018). The data-driven project manager. A statistical battle against project obstacles. Gent: Apress.

Wang, Q. (2019). How to apply AI technology in project management. PM World Journal, 8(3), $1-12$.

Wauters, M., \& Vanhoucke, M. (2014). Support vector machine regression for project control forecasting. Automation in Construction 47, 92-106.

Winter, R. (2016). Analytische informationssysteme aus managementsicht: Lokale entscheidungsunterstützung vs. unternehmensweite informations-infrastruktur. In Gluchowski \& Chamoni (eds.) (pp. 67-95, in German).

Yan, Y., Kuphal, T., \& Bode, J. (2000). Application of multiagent systems in project management. International Journal of Production Economics, 68(2), 185-197.

\section{Authors' Biographies}

Dr. Gunnar Auth is a full professor for Business Information Systems at Leipzig University of Telecommunications (HfTL), Germany. He completed his master's degree in business information systems at the University of Bamberg, Germany, and received a Ph.D. in economics from the University of St. Gallen, Switzerland. He started his professional career as an internal consultant at DaimlerChrysler where he worked in several management positions in logistics, operations and quality management. Before assuming his current position, he

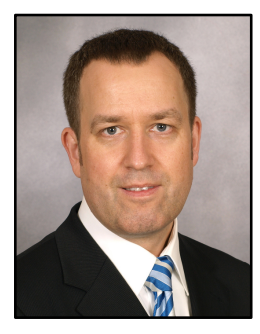
was IT director and representative of the CIO board at Leipzig University. His research focuses on IT project management, IT service management and information management. 
Dr.-Ing. Oliver Jokisch is teaching as a professor for signal and system theory at the Leipzig University of Telecommunications (HfTL), Germany. He studied information technology at TU Dresden in Germany as well as at the Loughborough University in United Kingdom. Oliver graduated as a diploma engineer and holds a $\mathrm{PhD}$ degree in information technology from TU Dresden. His research is dedicated to different AI areas and audio/speech communication such as audio coding, speech prosody and synthesis or language learning

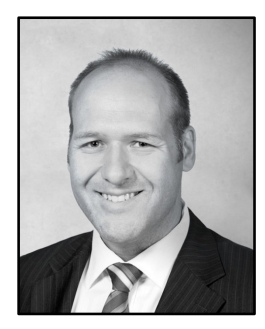
systems. Oliver has co-founded or mentored the IT-oriented companies voiceINTERconnect $\mathrm{GmbH}$, Linguwerk $\mathrm{GmbH}$, COSEDA Technologies $\mathrm{GmbH}$ and ambisone $\mathrm{GmbH}$ as well as the education and knowledge management firm IBWM GmbH.

Christian Dürk is Managing Director of the consulting firm CORIVUS AG and one of the company's very first employees. Graduated in industrial engineering he has more than 15 years of experience in managing complex IT and organizational projects. One of his specialties is the balancing act between turning a project at a short notice and its long-term organization - in particular, sustainable personnel planning that ensures the more permanent functioning of a business area. He lives with his wife and three children on the German

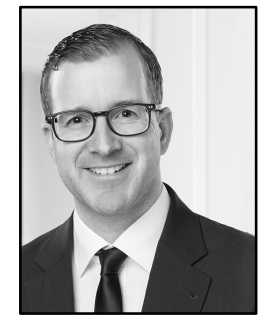
"Weinstrasse". 